\title{
EMPOWERING UNIVERSITY STUDENTS THROUGH ONLINE MULTIPLE CHOICE QUESTIONS
}

\author{
Biggins $^{1}$, D., Bolat ${ }^{2}$, E., Crowley ${ }^{3}$, E., Dogan ${ }^{4}$, H., and Dupac ${ }^{5}$, M. \\ ${ }^{1}$ Faculty of Management, Bournemouth University, UK \\ ${ }^{2}$ Faculty of Management, Bournemouth University, UK \\ ${ }^{3}$ Library Services, Bournemouth University, UK \\ ${ }^{4}$ Faculty of Science and Technology, Bournemouth University, UK \\ ${ }^{5}$ Faculty of Science and Technology, Bournemouth University, UK
}

\begin{abstract}
The benefit of using online multiple choice questions (MCQs) to test knowledge acquisition, provide reassurance to learners that required knowledge has be understood and as a tool to detect knowledge deficits or misunderstanding have long been understood. Moving the MCQ online provides an opportunity to widen access, measure participation and interaction and to test the use of theories such as gamification in raising engagement by students. Aim of this paper is to describe how Bournemouth University developed, integrated and operated the MCQ application, Peerwise, to enhance the engagement and learning of undergraduate and postgraduate students in the context of flipped class environment.

Using Peerwise, students create MCQs that are answered, rated and commented on by other students. Trophies awarded for contribution, feedback and usage ensure there is interest in the ranking tables and encourage higher levels of participation. Fielding's ${ }^{[1]}$ student as researcher concept is applicable here as students can use this tool to bring about radical change in their learning ${ }^{[1]}$. The traditional tutor - student relationship is often seen as a demotivator for students ${ }^{[2]}$ whereas Peerwise replaces this with self-regulated learning and a more flexible model that can be accessed at any time, from anywhere and which, crucially, gives immediate feedback and explanations. Issues surrounding the length of time taken to provide feedback and the utility of that feedback are instantly overcome. This personalised and empowering approach enables students to develop their knowledge appropriately as they undertake individual transformations ${ }^{[3]}$.

Bournemouth University embedded Peerwise in UG units. In line with previous studies ${ }^{[4][5]}$ Peerwise is found to be beneficial. After the successful trial, Bournemouth University has widened the use of MCQ through a staff-student co-creation project to generate university-wide question repositories that can be quickly and easily embedded in most taught units and which can also be used to give tutors experience and confidence in using a new technology-based learning tool and in this way to develop their own digital literacy. Peerwise allows improving student engagement by empowering students to regulate own learning processes.
\end{abstract}

Keywords: Multiple-choice questions, assessment, technology-enabled assessment, self-regulated learning space

\section{INTRODUCTION}

Assessment is always seen as controversial subject with majority of students being dissatisfied with whatever forms of assessment are on offer ${ }^{[6]}$. Nevertheless, assessment is at the heart of curriculum and presents opportunities to measure and monitor individuals' progress in the learning journey. In the meantime assessment has always adapted conventional and try-and-tested approaches of oral and written examinations, essays, MCQs and others. Most of assessment forms could, however, be adapted and modified in the context of technology-enhanced blended learning. Having said that the essence of assessment remains the same with new content formats and new submission platforms testing similar learning outcomes as traditional written essay.

Advancements in technological applications have transformed learning landscapes and pedagogical practices. Few examples of interesting ways to engage students in learning using technology are (1) incorporation of business simulation games in teaching entrepreneurship, (2) use of social media networks to communicate with students and facilitate group learning, (3) use of virtual class 
technology to connect learners and imitate in-class group discussions. However, technology integration into assessment part of learning experiences so far remained as contextual in nature enabling flexibility with no time and location constraints. Given all technical and network capabilities of internet-enabled technologies, educators need to consider how conventional forms of assessment become not only one off occasions to test knowledge but turn into critical part of self-directed learning experiences with elements of feedback, feedforward and peer-to-peer learning.

The benefit of using online multiple choice questions (MCQs) to test knowledge acquisition, provide reassurance to learners that required knowledge and as a tool to detect knowledge deficits or misunderstanding have long been understood. Conceptually, online MCQs should provide an opportunity to widen access, measure participation and interaction and to test the use of theories such as gamification in raising engagement by students. But is this the case? Are there technological applications that can use traditional MCQs with such benefits of technology-enhanced learning as content co-creation, peer-to-peer assessment, interactivity and creativity? Hence, aim of this paper is to describe how Bournemouth University developed, integrated and operated the MCQ application, Peerwise, to enhance the engagement and learning of undergraduate and postgraduate students in the context of flipped class environment.

The paper is structured as follows. Existing literature on technology-enhanced learning, self-directed learning and student engagement is discussed to assist analysis of the Peerwise case study. Method including details on the Peerwise case is outlined followed by discussion of results and implications for theory and practice.

\section{THEORETICAL BACKGROUND}

\subsection{Technology-enhanced learning}

Technology-enhanced blended learning is not a novel concept but essentially underpins $21^{\text {st }}$ century pedagogical practices. Fig. 1 outlines all facets of learning process that can and are benefiting from the integration of technology. As such technology enable learners to experience deep learning, therefore, achieve high level of cognitive engagement with the subject knowledge (Bloxham 2007).

Fig. 1. Overview of $21^{\text {st }}$ century technology-enhanced pedagogy

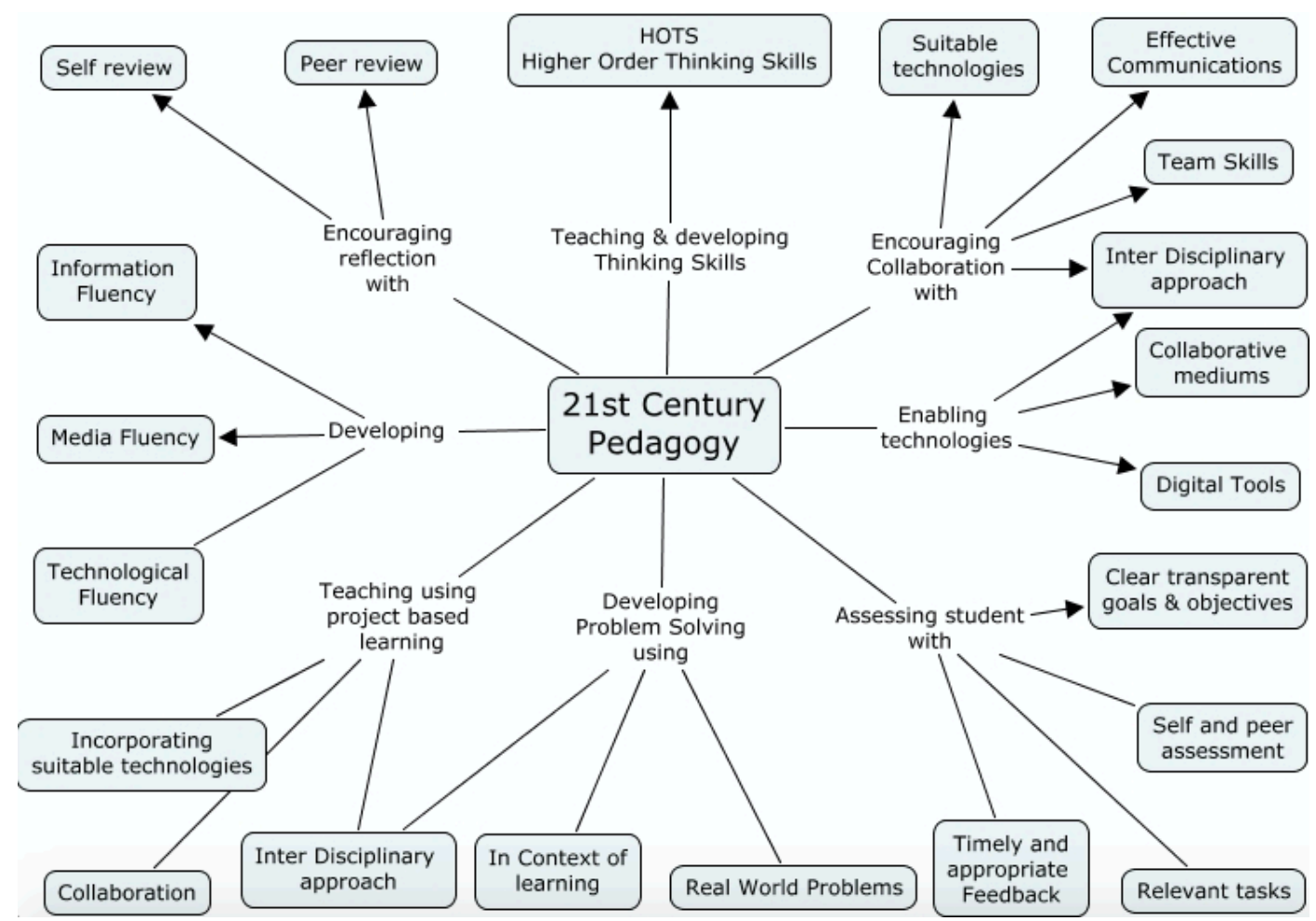

Source ${ }^{[17]}$ : Beetham, H. and Sharpe, R., 2013, "Rethinking pedagogy for a digital age: Designing for 21st century learning". Routledge. 
Technology-assisted assessment and feedback is one of facets within a learning process that demonstrates positive impact on both educators and students. Firstly, technology enables production of accessible and richer in terms of details and forms feedback ${ }^{[7][8][9][10][11]}$. Secondly, technology drives efficiency and productivity in assessment and feedback provision process allowing to produce comprehensive and detailed feedback in a reasonably short periods of time ${ }^{[12]}$. Finally, technology improves students engagement with the assessment and feedback as students feel empowered to have control over technological features as well as assessment conduct with reasonable flexibility over place and time of where and when to be assessed ${ }^{[7][9][10]}$.

Essentially technology is about blending conventional physical means of learning with technological means of interactivity, richness of content and convenience vis-à-vis location and time independence. Ideally both means are best to be blended to deliver benefits of both contexts. Today excellence in such blend is well evidenced through the notion of flipped classroom. Flipped classroom essentially speeds up learners' journey through Blooms taxonomy of learning through individual selfunderstanding of key terms towards collaborative practices of application, evaluation and creation. Having said that flipped classroom is seen challenging to be employed to the assessment processes, as when assessing individuals' contributions within the context of collective in-class discussions is pretty much impossible and questionable. Technology potentially plays an instrumental role in tracing individuals' progress and skills of evaluation, analysis and creativity. To date literature demonstrates how flipped classroom environment benefits assessment of group-based learning. However, evidences of assessing individual knowledge are limited.

In times when young professionals are expected to demonstrate digital skills in creating online content, storytelling, engagement with digital media, it is important to test individual learners' skills and knowledge. How beyond personal learning spaces like social media network to create blended learning spaces where students experience self-directed learning and allow educators to trace and understand and evaluate individual students' skills remains underexplored. How to assess students in conventional way but allow benefit from all user-related and technical capabilities of technologyenhanced education? Is it possible to use MCQs, which are aimed at testing subject knowledge, but to enable development of digital skills in the flipped classroom setting?

\subsection{Challenges of engaging Millennials with learning and assessment}

Millenial learners are digitally savvy, relatively independent decision-makers who grew up in a expanded bubble of internet-enabled connections ${ }^{[13]}$. They consume knowledge and learn through freely accessible content and on the basis of conversations which are authentic but co-constructed through extensive network of people ${ }^{[13]}$.

The engagement of students with learning in offline and online context has received an ample attention from educational scholars. Bloxham ${ }^{[7]}$ and Entwistle ${ }^{[14]}$ argue that low levels of engagement with learning are evidenced in student seeking to simply demonstrate knowledge through the grades and scores, hence, focus on doing well at the assessment stage of the learning process. Opposite to that high levels of engagement with learning are shown by students who seek to experience, experiment and create new interpretations of knowledge, therefore, focusing on pockets of interaction with literature, educators and discussion of various ideas with intention to achieve own understanding and explanation. Assessment for students with high level of engagement is not ultimate goal but part of the learning experience and knowledge acquisition process.

In the light of such differences, MCQs are often seen as method of assessing surface knowledge, hence, feeding the needs of students with low levels of engagement. It is therefore unsurprising to see less and less examples of utilising MCQs as assessment strategy, in social sciences and higher education contexts particularly. Is this the end of traditional and quite effective way of assessing subject knowledge? Perhaps not if MCQs are facilitated in the context of personal and shared technology-enabled learning spaces with intention to engage both students with low land high levels of engagement. Further, in this paper we discuss how Peerwise, an online repository of multiple choice questions (MCQs) that students create, share and answer, was used as a learning and assessment tool that empowered students, improved essential for Millenial students digital skills and increased student engagement. 


\section{METHOD}

In this paper we illustrate and evaluate a case of Peerwise following an action research strategy that provides comprehensive evaluation of process and experiences through a continuous process of reflection ${ }^{[15]}$. Action learning process, according to Dall'Alba ${ }^{[16]}$, is a continuous task of ongoing learning, eventually leading to transformation of educational practices.

As mentioned in the previous section, Peerwise is an online repository of multiple choice questions (MCQS) that students create, share and answer. When creating questions students think about questions they design and ask, format of the content used to ask the question or format of the content for indicating responses. Various formats like external links, text, video, audio are available. Once the question is frames and proposed, students need to indicate the correct answer and a number of wrong or distracting answers. In doing so students have to provide an explanation for why the answer is correct. Students can group questions using tags, themes meaning that they do learn and practice how to categorise, built-in and break-down groups and collections of content - something seen as essential element of digital literacy. Another important aspect of Peerwise is gamification features which do assist in encouraging engagement among learners. Gamification feature consists on ratings for questions, answers, trophies, competitions, and performance dashboards with leader boards. These features tap into both extrinsic and intrinsic motivations of students. Morover, Peerwise was selected because it is stable, free to use, and is accessible to staff and students.

Teaching team of two academics has used and integrated Peerwise into teaching undergraduate second year and final year BA (Hons) Business Studies students as (1) formative assessment mechanism by educator 1 [E1] and as (2) summative assessment mechanism by educator 2 [E2]. In particular E1 used Peerwise as way of supporting students in preparation for final Digital Interactive Marketing unit examination and E2 assigned percentage (10\%) of the overall grade for the Advanced Project Management unit for the level of engagement and quality of contributions in Peerwise. Overall integration of Peerwise used similar set of steps for both units (see Fig.2).

Fig. 2. Peerwise integration and use steps

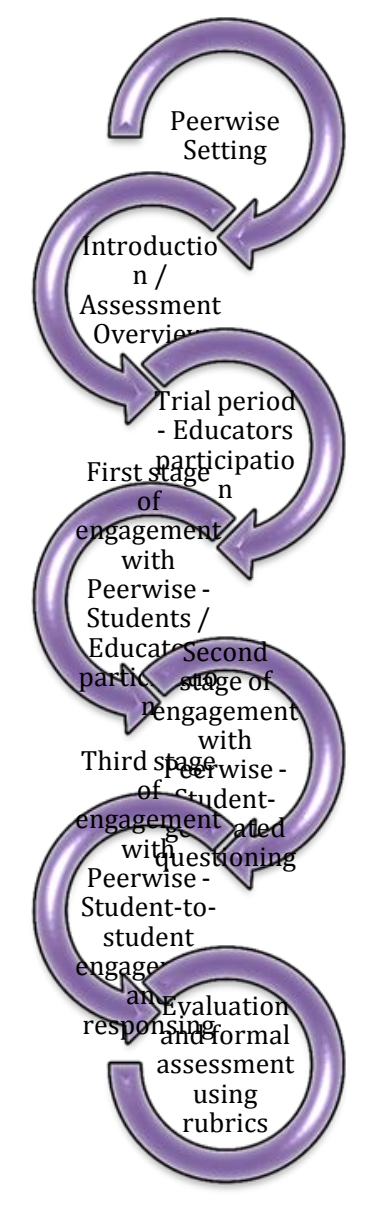


Firstly, Peerwise was integrated into units' documentation with detailed explanation and steps on setup, enrolment and initial engagement. Trial period commenced in the $1^{\text {st }}$ week of teaching when both educators demonstrated the use of Peerwise explaining its role in the learning process. Trial period expects high level of involvement by educators who can set expectations and demonstrate variety of ways in creating questions and proposing answers. Following trial period, three stages of engagement commenced: $1^{\text {st }}$ stage - educators engaging students in creation/response process with rewarding process in place of these student who demonstrate high levels of engagement with Peerwise integrating immediate feedback from educators; $2^{\text {nd }}$ stage - students at the top of league table actively creating content and being innovative with format, stories etc. integrating self-assessment of quality and quantity of generated questions/answers; $3^{\text {rd }}$ stage - active student-to-student engagement with creation/response process with intention to engage and motivate students demonstrating low levels of engagement integrating peer-to-peer assessment and in some instances, where applicable, place for debate. Final step constituted assessment, summative and formal, as well evaluation of overall Peerwise-enabled learning process.

\section{RESULTS AND DISCUSSION}

Overall evaluation of the engagement levels across steps has shown increase by $5 \%$ of students participation and engagement between trial period, $1^{\text {st }}$ and $2^{\text {nd }}$ stages. However, $3^{\text {rd }}$ stage resulted in dramatic increase of engagement, specifically in $2^{\text {nd }}$ case where E2 has formally assessment engagement with Peerwise. However, E1 case has also shown increase in engagement at the $3^{\text {rd }}$ stage. Perhaps this is due to the fact that students were taking over control in their own learning process, competing and engaging with the question creation/response process on a deeper level through motivation to challenge and be challenged. This is in line with existing literature. Hanrahan ${ }^{[2]}$ reported that the control the educator has over the learning process and curriculum demotivates students. $3^{\text {rd }}$ stage in particular enables a self-directed, independent learning approach with students taking the initiative to formulate and achieve goals they set for themselves ${ }^{[5]}$. Peerwise replaces this with self-regulated learning and a more flexible model that can be accessed at any time, from anywhere and which, crucially, gives immediate feedback and explanations. Issues surrounding the length of time taken to provide feedback and the utility of that feedback are instantly overcome. This personalised and empowering approach enables students to develop their knowledge appropriately as they undertake individual transformations ${ }^{[3]}$.

Conventional teaching sees the educator dispensing knowledge to disengaged students and motivating them using extrinsic factors such as grades. In student-empowered learning the student is responsible for planning, designing and running their personal learning spaces and processes. Educators' role in the case of Peerwise was using intrinsic factors to motivate students to engage, showing and using the tool by participating, picking peer leaders who then can encourage own peers in much more authentic and relevant ways. Students were then encouraged to learn for themselves, be self-reliant and take responsibility for their learning ${ }^{[18]}$.

Peerwise and online MCQs have overall increased student involvement in learning and demonstrated improvements in content creation, framing and evaluation skills of all students who engaged with Peerwise. Based on units' evaluation surveys, benefits of integrating Peerwise for students were (see Tab. 1 below):

- Students engagement has increased across the groups of students;

- Students turned formally introduced technological tool into personal learning space where they had control, courage and goals to engage, compete and challenge each other;

- There was no cost implication attached to the use of Peerwise and overall student felt there was additional value introduced to their overall student experience;

- Students developed and advanced digital skills, i.e. content creation, content sharing, content evaluation. 
Tab. 1. Results of the units' post-deliver evaluation surveys

\begin{tabular}{|c|l|}
\hline \multicolumn{2}{|l|}{ Findings } \\
\hline 1 & Accessing Peerwise was easy and use was intuitive. No training was needed. \\
\hline 2 & $\begin{array}{l}\text { Peerwise aids revision (100\% agree or strongly agree) and builds understanding } \\
(100 \% \text { agree or strongly agree). }\end{array}$ \\
\hline 3 & Earning trophies is motivational (70\% agree). \\
\hline 4 & Peerwise identifies gaps in knowledge (100\% agree or strongly agree). \\
\hline 5 & 24 hour access to Peerwise gives flexibility (100\% agree or strongly agree). \\
\hline 6 & For tutors, $90 \%$ said Peerwise would be useful for some or all of their units. \\
\hline 7 & $\begin{array}{l}\text { On a scale of } 1 \text { to } 10 \text { where } 1 \text { is very poor and } 10 \text { is excellent, students scored } \\
\text { Peerwise at } 7.6 .\end{array}$ \\
\hline
\end{tabular}

\section{CONCLUSIONS AND IMPLICATIONS}

Bournemouth University embedded Peerwise in UG units. In line with previous studies ${ }^{[4][5]}$ Peerwise is found to be beneficial to empowering students and encouraging them to become self-directed learners. Overall students' engagement has been consistently improved benefiting both students with originally low levels of engagement as well as these who have show high levels of engagement. Finally, students benefited from online MCQs from the professional skills development point of view by learning and experiencing content creation, management and evaluation in practice. This paper highlights that marrying online learning environment and traditional concept of using multiple choice question (MCQ) testing results in establishing empowering, motivating, and self-regulated learning spaces for university students.

After the successful trial, Bournemouth University has widened the use of MCQ through a staff-student co-creation project to generate university-wide question repositories that can be quickly and easily embedded in most taught units and which can also be used to give tutors experience and confidence in using a new technology-based learning tool and in this way to develop their own digital literacy. Peerwise allows improving student engagement by empowering students to regulate own learning processes.

This study is limited methodologically as it is based on a single case study. Evaluation of Peerwise experience is also quite subjective and interpretative in nature triggering questions about validity of the results and conclusions we made. Hence, more work is to be done in assessing longitudinal impact of using Peerwise on students as well as more cases to be evaluated and collected across various levels of studies.

\section{ACKNOWLEDGEMENTS}

We would like to thank Bournemouth University for supporting this project through internal funding as well as groups of students who helped to further expand integration of Peerwise in Bournemouth University's technology-enhanced learning system.

\section{REFERENCES}

[1] Fielding, M., 2001, "Students as radical agents of change", Journal of educational change, 2 (2), 123-141.

[2] Hanrahan, M., 1998, "The effect of learning environment factors on students' motivation and learning", International Journal of Science Education, 20 (6), 737-753.

[3] Biggs, J. and Moore, P., 1993, "The process of learning". New York: Prentice Hall.

[4] Denny, P., 2010. "Motivating Online Collaborative Learning", ITICSE 2010: Proceedings of the 2010 ACM SIGCSE Annual Conference on Innovation and Technology in Computer Science Education, ASSOC Computing Machinery, 2010.

[5] Luxton-Reilly, A., Denny, P., Plimmer, B., and Sheehan, R., 2012. "Activities, affordances and attitude: how student-generated questions assist learning", Proceedings of the 17th ACM annual conference on Innovation and technology in computer science education. 
[6] Shepard, L.A., 2016. "Testing and Assessment for the Good of Education Contributions of AERA Presidents", 1915-2015. Educational Researcher, 45(2), pp.112-121.

[7] Bloxham, S. and Boyd, P., 2007. "Developing effective assessment in higher education", Maidenhead, Open University Press.

[8] Challis, D., 2005. "Committing to quality learning through adaptive online assessment", Assessment and Evaluation in Higher Education, Vol 30, No 5, pp 519-27.

[9] Denton, P., 2003. "Returning feedback to students via email using Electronic Feedback", Learning and Teaching in Action, Vol 2, No 1.

[10] Denton, P., Madden, J., Roberts, M. and Rowe, P., 2008. "Students' response to traditional and computer-assisted formative feedback: A comparative case study", British Journal of Educational Technology Vol 39, No 3, pp 486-500.

[11] Heinrich, E., Milne, J., Ramsay, A. and Morrison, D., 2009, "Recommendations for the use of etools for improvements around assignment marking quality", Assessment and Evaluation in Higher Education, Vol 34, No 4, pp 469-79.

[12] HEFCE, 2007. "2007 Teaching Quality Information Data”, Higher Education Funding Council for England. Available from: http://www.hefce.ac.uk/learning/nss/data/2007/

[13] Ashley, C., \& Tuten, T., 2015. "Creative strategies in social media marketing: An exploratory study of branded social content and consumer engagement", Psychology \& Marketing, 32(1), 15-27.

[14] Entwistle, N., 2000. "Promoting deep learning through teaching and assessment: conceptual frameworks and educational contexts", In ESRC Teaching and Learning Research Programme (TLRP), First Annual Conference, University of Leicester, November 2000.

[15] Carr, W. and Kemmis, S., 2003, "Becoming critical: Education, knowledge and action research", London, Routledge.

[16] Dall'Alba, G., 2005, “Improving teaching: Enhancing ways of being university teachers”, Higher Education Research and Development, Vol 24, No 4, pp 361-372.

[17] Beetham, H. and Sharpe, R., 2013, "Rethinking pedagogy for a digital age: Designing for 21st century learning". Routledge.

[18] Bruner, J., 1990. "Acts of meaning", Cambridge: Harvard University Press. 